\title{
Surface Crack Detection in Prestressed Concrete Cylinder Pipes Using BOTDA Strain Sensors
}

\author{
Zhigang Xu, ${ }^{1,2}$ Xin Feng, ${ }^{3}$ Sheng Zhong, ${ }^{3}$ and Wenjing $\mathrm{Wu}^{3}$ \\ ${ }^{1}$ College of Mechanical and Electronical Engineering, China University of Petroleum (East China), \\ No. 66 Changjiang West Road, Qingdao 266580, China \\ ${ }^{2}$ Offshore Department, Sinopec Petroleum Engineering Corporation, No. 49 Jinan Road, Dongying 257026, China \\ ${ }^{3}$ State Key Laboratory of Coastal and Offshore Engineering, Dalian University of Technology, No. 2 Linggong Road, \\ Dalian 116023, China \\ Correspondence should be addressed to Xin Feng; fengxin@dlut.edu.cn
}

Received 15 March 2017; Revised 4 June 2017; Accepted 18 July 2017; Published 21 August 2017

Academic Editor: Roman Wendner

Copyright (C) 2017 Zhigang Xu et al. This is an open access article distributed under the Creative Commons Attribution License, which permits unrestricted use, distribution, and reproduction in any medium, provided the original work is properly cited.

Structural deterioration after a period of service can induce the failure of prestressed concrete cylinder pipes (PCCPs), with microcracks in the coating leading to the corrosion of the prestressed wires. In this paper, we propose the use of Brillouin optical time-domain analysis (BOTDA) strain sensors for detecting the onset of microcracking in PCCP coating: the BOTDA strain sensors are mounted on the surface of the PCCP, and distributed strain measurements are employed to assess the cracks in the mortar coating and the structural state of the pipe. To validate the feasibility of the proposed approach, experimental investigations were conducted on a prototype PCCP segment, wherein the inner pressure was gradually increased to 1.6 MPa. Two types of BOTDA strain sensors-the steel wire packaged fiber optic sensor and the polyelastic packaged fiber optic sensor-were employed in the experiments. The experimental distributed measurements agreed well with the finite element computations, evidencing that the investigated strain sensors are sensitive to localized deterioration behaviors such as PCCP microcracking.

\section{Introduction}

The number of long-distance water diversion projects is steadily increasing in China, for which prestressed concrete cylinder pipes (PCCPs) are widely adopted owing to their high load capacity. PCCPs used in such projects have diameters as large as $4 \mathrm{~m}$, bear inner pressures as high as $1.6 \mathrm{MPa}$, and are buried at depths of up to $12 \mathrm{~m}$. In modern PCCP applications, the ambient and load states have become increasingly complex, and the consequent structural deterioration after a period of service often results in pipe failure [1]. PCCP failure typically occurs suddenly and may have severe consequences such as contaminant leakage, transportation disruptions, injury, and even fatalities. To avoid such failure, monitoring technologies have been developed for obtaining a better understanding of the structural behavior of PCCPs, especially those with very large diameters, and for assessing their structural condition and accordingly executing appropriate maintenance activities.

Currently, methods for evaluating the structural condition of PCCPs include sonic, ultrasonic, electromagnetic (EM), and acoustic fiber optic (AFO) methods [2-4]. These technologies can detect such structural damage as cracks, delamination, and mortar thinning as well as the number and locations of broken wires. However, they have some practical limitations and disadvantages; for example, the sonic and ultrasonic technologies are not automated, and their application to long pipelines requires significant time. Because of the structural complexity of PCCPs, the EM approach has low accuracy in detecting broken wires at the ends of pipe segments. Moreover, both of these approaches do not support real-time monitoring of the entire length of a pipeline because their working principle is based on local detection. In addition, the AFO technology cannot 
detect broken wires in an empty pipe, and the EM and AFO technologies cannot identify the hoop location of a broken wire, a detail crucial for stress distribution analysis. Strain monitoring of pipelines using point or distributed fiber optic sensors (FOSs) was recently adopted [5]. Whereas point sensors enable more effective property measurement in terms of resolution, accuracy, and frequency, their high cost implies that they can only be sparsely distributed in practice; this results in significantly low spatial resolution, which makes detecting early-stage PCCP structural damage difficult. This practical shortcoming can be overcome using distributed sensors [6].

Environmental factors influence the corrosion of prestressed wires in PCCPs: cracks in the mortar coating function as passageways for external corrosive media to reach the prestressed wires and initiate corrosion, which eventually causes wire breakage and the sudden structural failure of PCCPs. Therefore, detecting surface cracks in PCCPs can serve as an early warning of structural failures. This study proposes an approach for the surface crack detection of largediameter PCCPs by using Brillouin optical time-domain analysis (BOTDA) strain sensors for early damage detection. The feasibility of the present approach, including the use and installation of FOSs, was studied through inner pressure tests on PCCP segments, following which the test results were validated through comparison with numerical simulations.

\section{Materials and Methods}

2.1. Monitoring Scheme. To develop an effective monitoring scheme, the PCCP failure mechanism must first be analyzed. Prestressed wires are the most important load-carrying components of a PCCP. The most frequent cause of PCCP failure is corrosion-induced wire breakage, which decreases the structural strength of the pipe: initially, overloading can induce microcracks in the pipe coating, which thereafter serve as passageways for external corrosive media to arrive at and initiate corrosion of the prestressed wires. As the pipe ages and the corrosion progresses, the prestressed wires eventually fracture through hydrogen embrittlement or stress corrosion, which further generates more cracks and causes delamination of the concrete core and coating; this makes it easier for the underground water to reach the prestressed wires and induce further corrosion and breakage. Hence, the structural degradation of a PCCP is a coupled process influenced by the service and load conditions. When a critical number of prestressed wires break, the concrete core crushes, the cylinder fractures, and finally the PCCP loses its structural integrity.

As explained, the generation of microcracks in the PCCP coating initiates the structural deterioration. Cracking in the coating can thus serve as a reliable early warning of PCCP damage, and critical information on the structural performance of the pipe can be acquired through crack monitoring.

A challenge in crack detection in the PCCP coating is that the crack location cannot be obtained in advance, which necessitates the distributed FOS technique. Distributed FOSs identify and locate cracks on the basis of sensor topology (i.e., the positions of the FOSs). The appropriate sensor topology can be determined considering the expected failure mode of the PCCP, which in turn relies on the structural states and deterioration condition of the pipe: the combination of the earth load and inner pressure may lead to the hoop deformation of the pipe, whereas longitudinal bending caused by the earth pressure and the bedding states may induce pipe deflection. When the critical stress is reached, cracking of the coating is initiated, resulting in strain singularity. The distributed FOSs investigated in [7-9] could detect the strain singularity induced by the cracking in a structure.

A parallel sensor topology in both the longitudinal and the hoop orientations on the surface of a PCCP is the most feasible for detecting coating cracking. The parallel topology used for the hoop strain measurements in the present study utilized at least three parallel strain sensors in each pipe segment: one sensor placed $1 \mathrm{~m}$ from each end of the segment and the third placed at the middle; and the parallel topology used for longitudinal sensing comprised four parallel strain sensors in the longitudinal direction, mounted on the pipe crown, the pipe invert, and the spring lines (Figure 1). For field applications, all FOSs on the different PCCP segments, including the hoop and longitudinal strain sensors, were connected to construct a sensor loop for distributed strain sensing. In field applications, the temperature compensation should be considered for distributed strain measurements. As shown in Figure 1(a), two loose cables inside the protection tubes are placed along the pipe crown and pipe invert, respectively. The environmental temperatures along the pipeline can be obtained from the two loose optical cables. At an arbitrary cross section, the temperatures between the pipe crown and pipe invert can be interpolated from the measured values of the two loose cables. And hence the independent temperature compensation is achieved for BOTDA strain sensors.

2.2. Installation Techniques. BOTDA was first proposed by Horiguchi et al. [10] for the distributed measurement of strain in an optical fiber. In this technique, distributed FOSs are realized using a single optical cable susceptible at each point along the fiber path, meaning that a single optical fiber replaces numerous point sensors in a distributed manner. In addition, such a distributed FOS is easier to install and its output is more favorable in terms of operation and maintenance. Review of the technical literature reveals that the basic theory pertaining to the operational characteristics of BOTDA has been detailed in the technical literature. The BOTDA sensor system utilizes the backward stimulated Brillouin scattering (SBS) of an optical fiber. The pumping pulse light is launched at one end of the fiber and propagates in the fiber, while the continuous (CW) light is launched at the opposite end of the fiber and propagates in the opposite direction. The measuring principle of BOTDA sensing system is shown in Figure 2. In this configuration, the pump pulse generates backward Brillouin gain in a single-mode fiber. When the CW light frequency is different from the pump pulse light same as the Brillouin frequency of the optical fiber, then the CW light is amplified through Brillouin interaction with the pump pulse. Also, the Brillouin frequency of a fiber is changed by the strain or temperature applied on the 


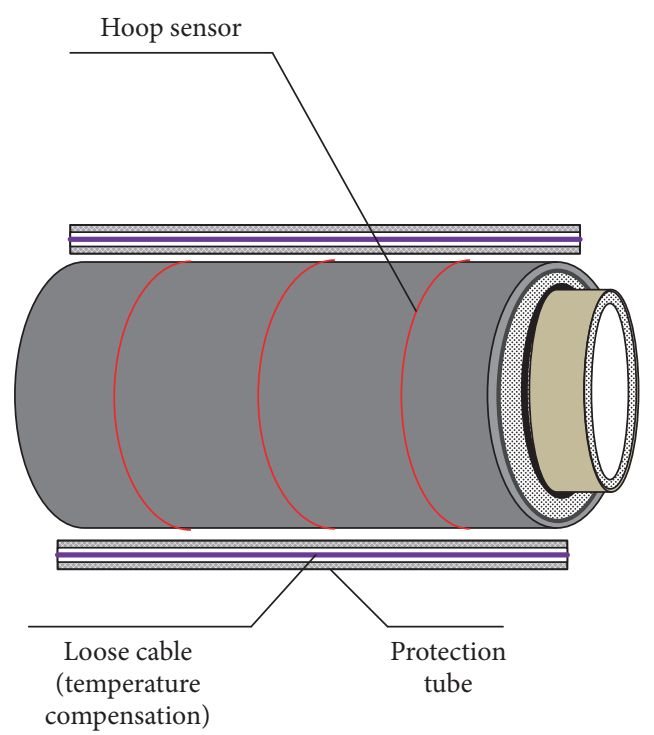

(a) Elevation view

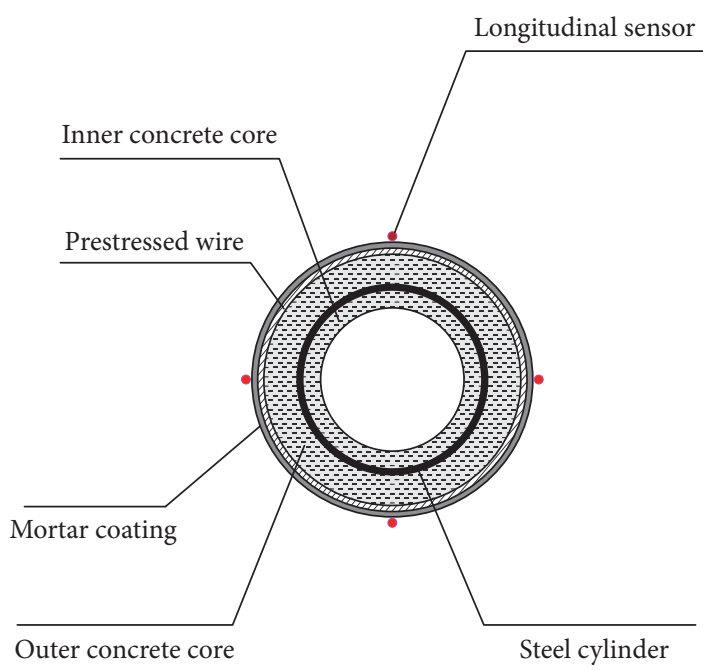

(b) Cross-sectional view

FIgUre 1: Topology of distributed FOSs on a PCCP segment.
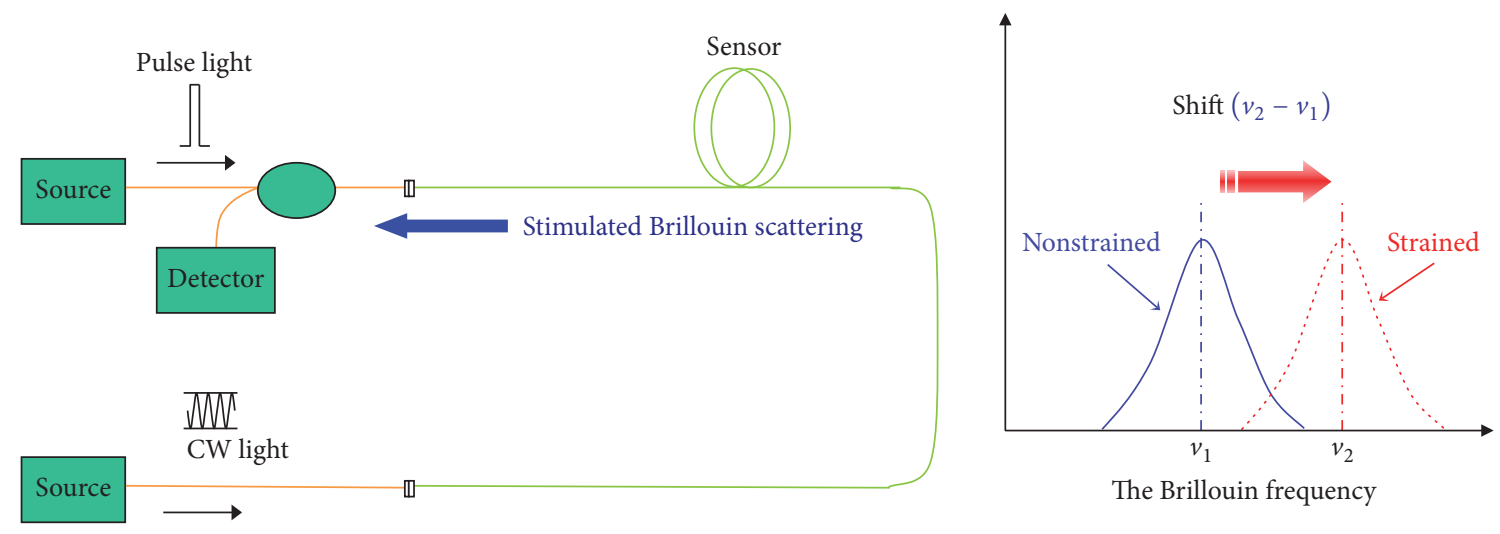

FIGURE 2: Measuring principle of BOTDA.

fiber. Therefore, the Brillouin frequency shift at the arbitrary location along the fiber can give the temperature or strain information as the following equation:

$$
v_{B}(\varepsilon, T)=C_{\varepsilon} \cdot \varepsilon+C_{T} \cdot T,
$$

where $C_{\varepsilon}$ and $C_{T}$ are the strain and temperature coefficients, respectively, and $v_{B}$ represents the Brillouin frequency shift. $\varepsilon$ and $T$ mean the strain variation and temperature variation, respectively. According to (1), once the temperature variation is obtained or the temperature is unchanged during the measurement, the strain variations can be distributed, determined with the measured Brillouin frequency shift.

The conventional BOTDA technique has limitations in the spatial resolution and sensing range. To overcome the drawbacks of conventional BOTDA, the differential pulsewidth pairs BOTDA approach [11, 12] was proposed for longrange $(>60 \mathrm{~km})$ measurements. Kishida and Li [13] proposed the pulse prepump BOTDA (PPP-BOTDA) for measurement with a $\mathrm{cm}$ order spatial resolution. This study does not focus on the BODTA measuring instrument itself but on the application of BOTDA strain sensors to PCCP: if the feasibility of surface crack detection using the BOTDA sensor is established - which is the objective of this study - then the appropriate BOTDA measuring technique according to the in situ monitoring conditions can be applied.

The selection and installation of an appropriate sensor are critical issues in the BOTDA-based approach. The performance of the distributed FOSs depends on the employed packaging technique; therefore, a package that ensures high strain transfer from the substructure to the optical fiber must be selected. Moreover, the package should effectively protect the inner optical fiber. Thus, in the present study, we investigated which of the two types of BOTDA strain sensors-the steel wire packaged FOS (SWPFOS) and the polyelastic packaged FOS (PEPFOS) - is appropriate for application to large-diameter PCCPs. These two FOSs were selected after a review of several potentially useable FOSs on the basis of their industrial application. 


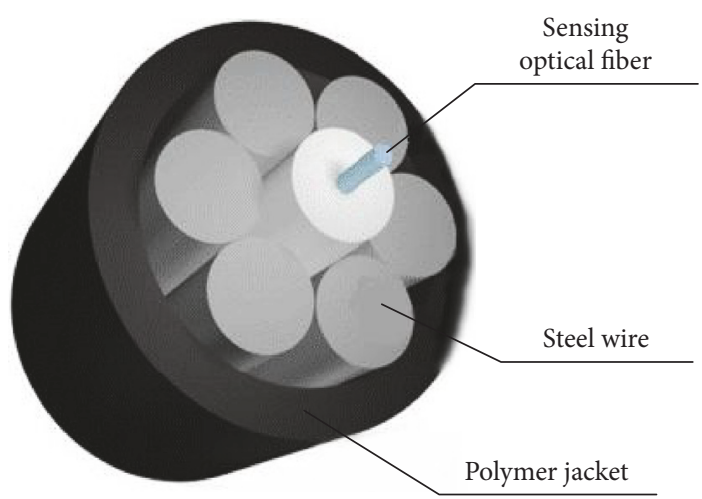

(a)

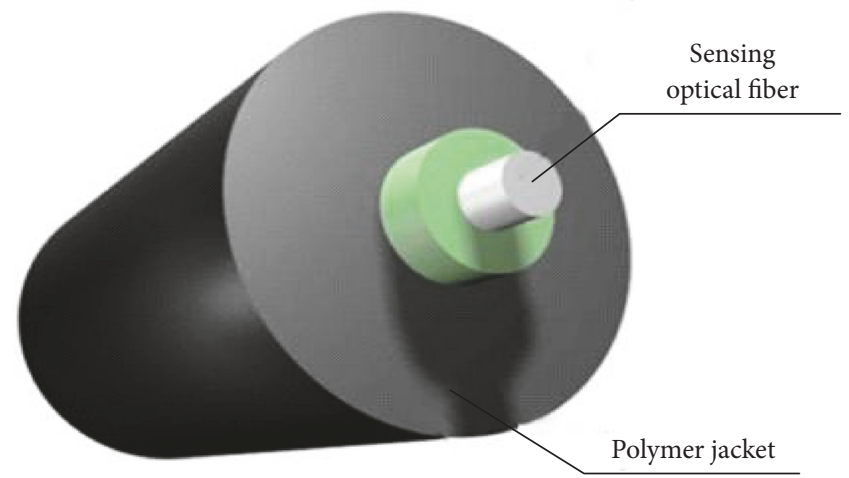

(b)

FIgURE 3: Schematics of the two employed FOSs: (a) SWPFOS and (b) PEPFOS.

The SWPFOS comprises an optical fiber, five strands of steel wires, and an outer polymeric jacket. This FOS has the advantage of strong mechanical protection afforded by the spiral steel strands (Figure 3(a)). However, it has low sensitivity to local damage in the monitored structure, and its large size makes bonding with the substructure difficult. The PEPFOS comprises an optical fiber and a high-strength polymeric jacket (Figure 3(b)). Its small size and high strain transfer render it highly sensitive to incipient damage, such as cracks in the surface of the monitored structure. For SHM applications, the long-term behavior of the sensors and their dependence on the environmental conditions are also critical issues. The environmental effects on the long-term performance of the sensors, including humidity, freeze-thaw cycles, and soil pressure, were experimentally investigated [14]. The results demonstrate that the two kinds of sensors have good long-term performance for pipeline monitoring.

As mentioned earlier, the method used to bond the sensors to the structure is a key concern in distributed monitoring. Based on the dimensions and performance of the two aforementioned sensors, two installation techniques are proposed in this study: surface bonding and embedding. In surface bonding, the distributed FOS is glued to the outer surface of the PCCP, and in embedding, $5 \times 5 \mathrm{~mm}$ grooves are created on the coating, into which the sensing cable is clamped. In both cases, after bonding with the high-strength cement coating, the sensors are covered with epoxy resin. Validation tests revealed that both approaches facilitated strain transfer, with surface bonding requiring less time. Thus, surface bonding is recommended for in situ applications.

2.3. Experimental Setup. To verify the feasibility of the presented approach, full-scale experimental investigations were performed using the aforementioned distributed sensing technique. The apparent diameter and length of the PCCP test segment were 3.8 and $5 \mathrm{~m}$, respectively. The design inner pressure of the pipe was 0.6 MPa. During the tests, one end of the PCCP segment was fixed to a static water pressure test platform.
The pipe was first fixed in the test platform, following which the distributed FOSs were placed using the two abovementioned methods in separate experiments. One hoop FOS each was placed $1 \mathrm{~m}$ from the top and bottom of the PCCP, and another was placed at the middle. The longitudinal FOSs were installed on the PCCP from the top to the bottom, displaced at $90^{\circ}$ from the cross section. In the embedding method, the PEPFOSs were installed on three circles, whereas in the surface-bonding method, the SWPFOSs were placed on the lower and central circles. The two approaches were also separately used to install the two investigated sensors for longitudinal sensing. All BOTDA strain sensors were connected using lead fibers to build a sensing network for distributed monitoring of the experimental PCCP. A BOTDA sensing system (NBX-6050A, Neubrex Inc., Japan) was used for the distributed strain measurements. For accurate measurement, the spatial resolution was set to $10 \mathrm{~cm}$, and the sampling distance interval was set to $5 \mathrm{~cm}$. The sensor setup and instrumentation are depicted in Figure 4. According to the user manual, the accuracy of the PPP-BOTDA analyzer is $\pm 5 \mu \varepsilon$. However, in practice, the measurement accuracy depends on such factors as the sensor used and the installation method. Therefore, the practical accuracy tends to be slightly lower than that reported in the manual. Before the actual experiments, the concrete beams were subjected to preliminary experiments. The results indicated that the proposed sensor and installation method have an acceptable accuracy of $\pm 20 \mu \varepsilon$.

Simulating actual load combinations on a full-scale pipe segment is difficult in a feasibility study. In the present study, the testing PCCP segment was loaded using a suite of inner pressures. Seven loads were applied in accordance with the Chinese code GB/T 19685-2005 (Table 1) [15]. The largest applied load of 1.6 MPa far exceeded the design inner pressure and was expected to induce cracking in the mortar coating. Note that the proposed sensor topology pertains to monitoring the deformation of PCCP under all hoop and longitudinal loads. Different load combinations result in differential strain/stress responses in the PCCP, but the critical cracking strain of the mortar coating is a 
TABLE 1: Applied test loads.

\begin{tabular}{lccccccc}
\hline Case & 1 & 2 & 3 & 4 & 5 & 6 & 7 \\
\hline Inner pressure $(\mathrm{MPa})$ & 0.4 & 0.6 & 0.8 & 1.0 & 1.2 & 1.4 & 1.6
\end{tabular}
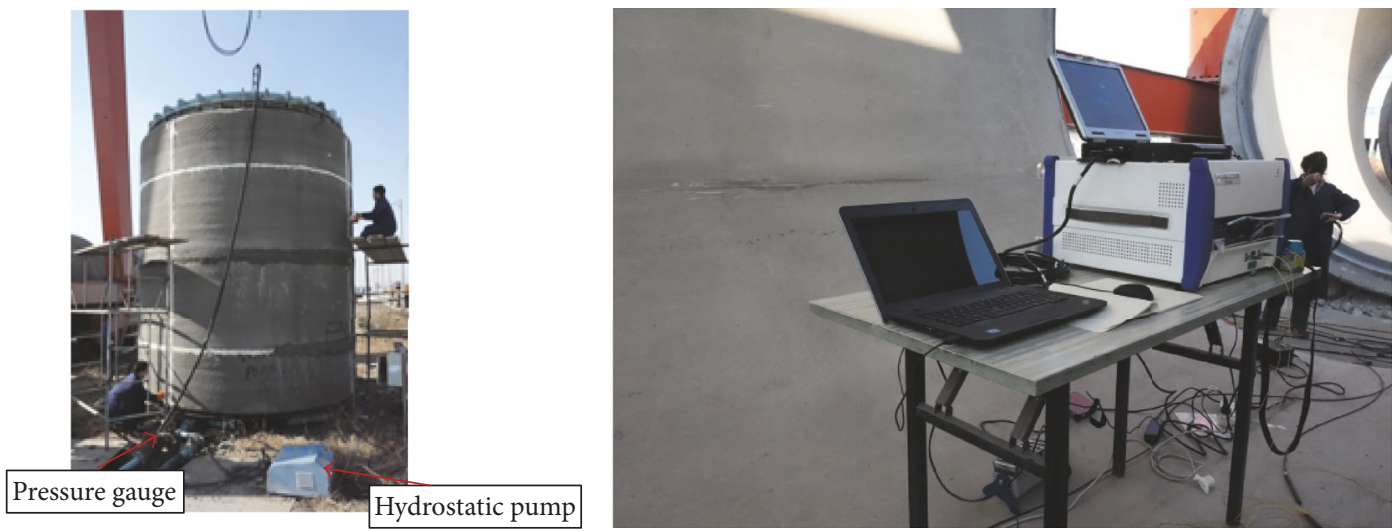

FIGURE 4: Sensor setup and instrumentation.

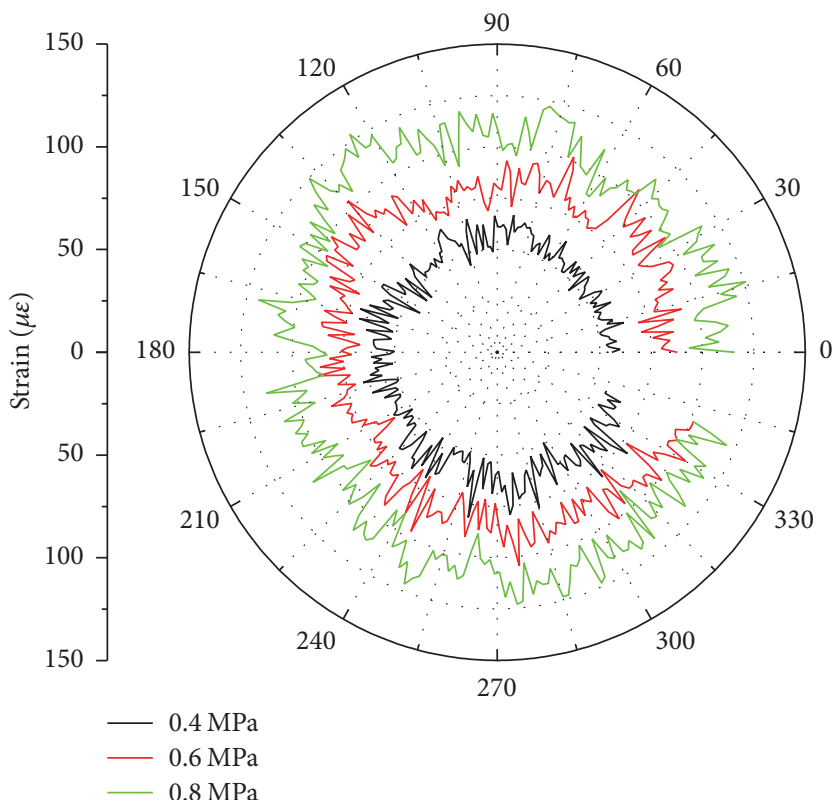

(a)

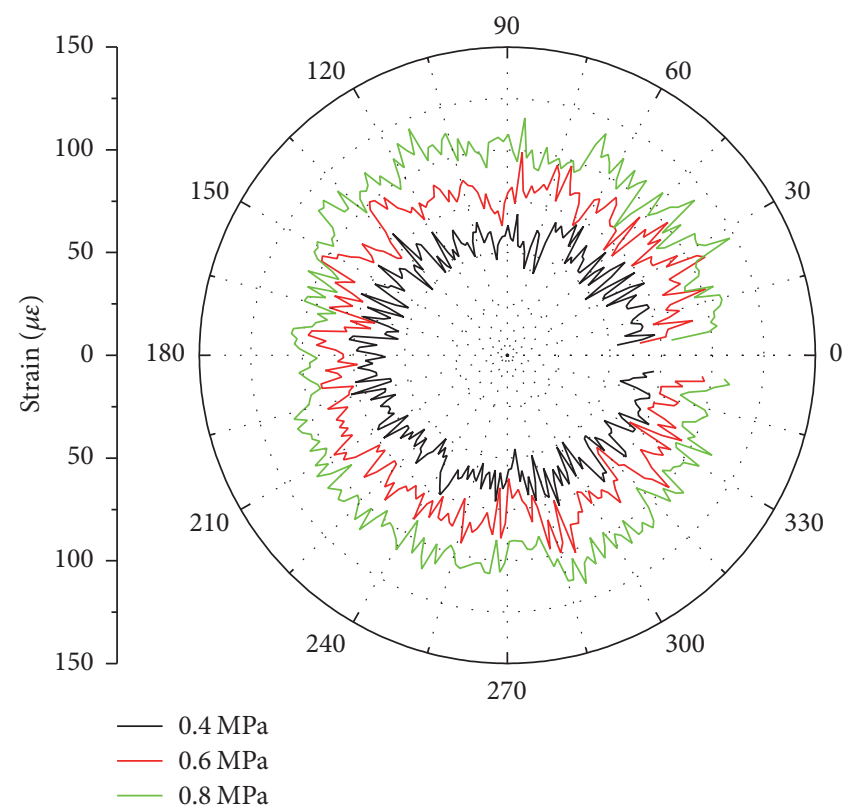

(b)

FIGURE 5: Strains measured using SWPFOSs for the first load cases 1-3: (a) lower circle, (b) middle circle.

constant under all combinations. The primary objective of the proposed method is accurate strain measurement and singularity detection. Thus, the crack detection performance of the proposed method can be reasonably examined using the aforementioned load pattern.

At every loading level, the inner pressure was measured using a pressure gauge. After the inner pressure stabilized, distributed strain measurements were performed using the BOTDA sensing system.

\section{Results and Discussion}

3.1. Hoop Strain Measurement Using SWPFOS. In this study, the hoop and longitudinal strains were distributively monitored using two BOTDA sensors. The longitudinal measurements were of low magnitude even under large loads and are therefore not reported in this paper.

Figure 5 illustrates the SWPFOS measurements for load cases 1-3. The hoop strains detected by the sensors at the 


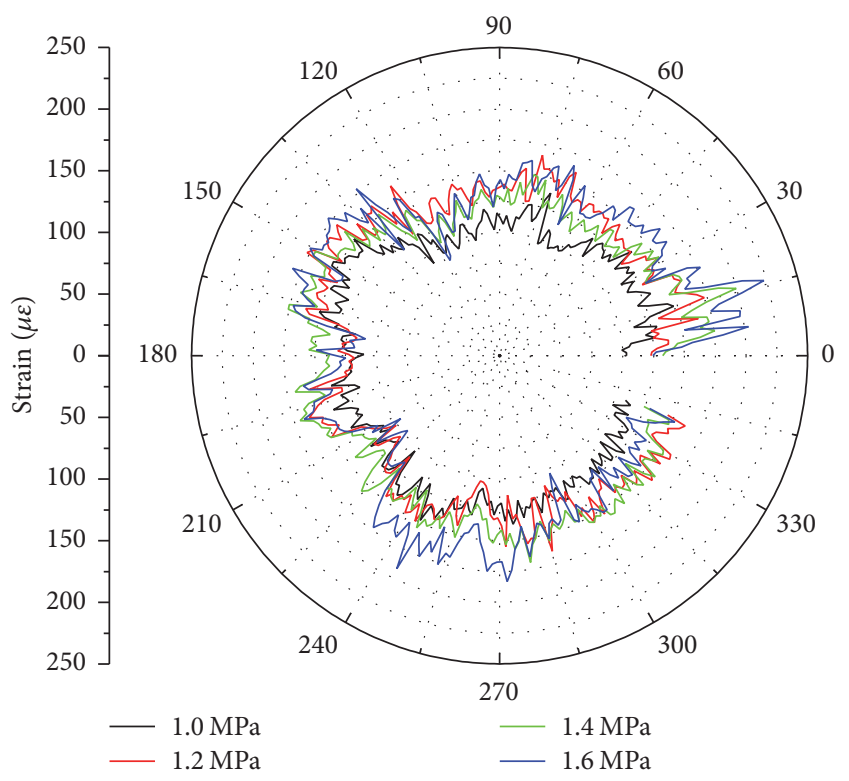

(a)

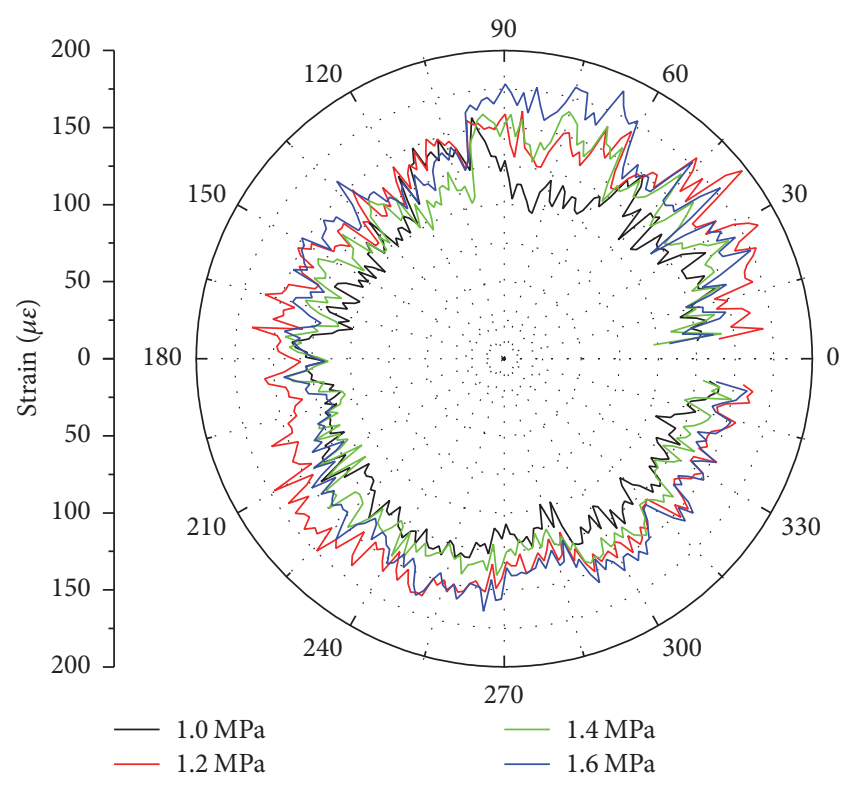

(b)

FIGURE 6: Strains measured using SWPFOSs for load cases 4-7: (a) lower circle, (b) middle circle.

lower and central circles were nearly the same for each load. In addition, the hoop strain increased with the increase in the load. However, the measured strain fluctuated slightly because of imperfect senor installation and measurement. The average strains in the lower, middle, and upper loops were approximately 60,80 , and $100 \mu \varepsilon$, respectively.

Figure 6 presents the SWPFOS strain measurements for load cases 4-7. The measurements at the lower and middle loops are in good agreement. However, the measurements at the middle loop exhibited large fluctuations, indicating that the structural behavior under loads 4-7 differs compared with that of cases $1-3$. The damage to the test pipe, however, cannot be determined from the irregularities in the measured data.

3.2. Hoop Strain Measurement Using PEPFOS. PEPFOSs were used to measure hoop strains at the lower, middle, and upper circles of the experimental PCCP. The measurements at the three circles under cases 1-3 exhibited good agreement (Figure 7), highlighting the high accuracy of the BOTDA strain sensors. The PEPFOS measurements are slightly larger than that of SWPFOS (Figure 5); this is due to the more effective strain transfer in the PEPFOS afforded by its lower stiffness.

Irregularities appeared in the strain data from load case 4 onward (Figure 8). Moreover, the number of data irregularity points increased with the increase in the inner pressure, and the very large measured strains indicate damage to the PCCP coating. Furthermore, the points at which strain tends to be zero or negative are suggestive of destruction of the bonding interface between the BOTDA sensor and the structure, which is a result of structural defect-induced strain singularity in the PCCP coating. Because of the uncertainties in the onset of the surface defects, the positions of the strain singularities at the lower, middle, and upper circles differed. This result demonstrates the benefits of a distributed sensor, which enables determination of the global strain shape in the hoop directions. However, whereas singularities involved in the structural defects of the PCCP could be identified using the BOTDA strain sensors, no visible cracks were observed during the tests.

3.3. Numerical Simulations. To interpret the experimental phenomenon, numerical simulations of the test pipe were performed using Abaqus software and the discrete finite element model. The solid element C3D8R was used to model the PCCP core and coating, and the shell element was used to discretize the steel cylinder. The truss element was employed to model the prestressed wires, and the prestressing load was applied using the temperature drop method. The mortar coating and concrete core were simulated using the concrete damaged plasticity (CDP) constitutive relationship, and the steel cylinder and prestressed wire were modeled using the elastic-perfectly plastic constitutive law. The CDP model is a continuum, plasticity-based, damage model for concrete. It assumes that the main two failure mechanisms are tensile cracking and compressive crushing of the concrete material. The detailed description of CDP model can be found in Abaqus Analysis User's Manual [16]. Owing to space constraints, only the stress-strain curves of concrete and cement mortar in the computations are plotted in Figure 9. The stress-strain curves in the figure were provided by the pipe producer according to the material tests during the manufacture process. The peak stress of mortar is approximately $3.5 \mathrm{MPa}$ under tension, beyond which the mortar enters the nonlinear damage stage. When the strain exceeds $8 \varepsilon_{\mathrm{t}}^{\prime}$ ( $\varepsilon_{\mathrm{t}}^{\prime}$ is the strain corresponding to the peak stress), visible crack forms in the mortar material. To simulate the actual 

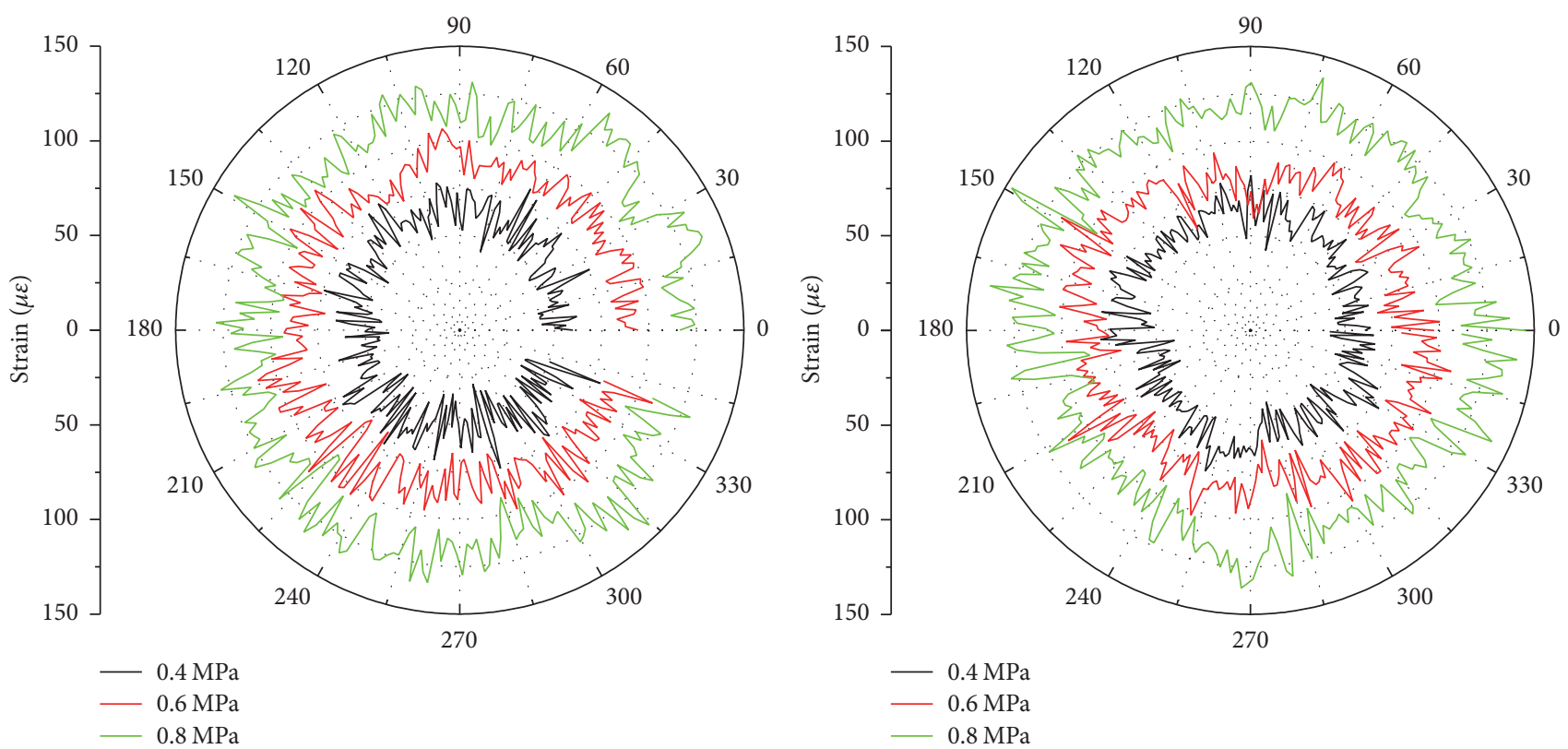

(a)

(b)

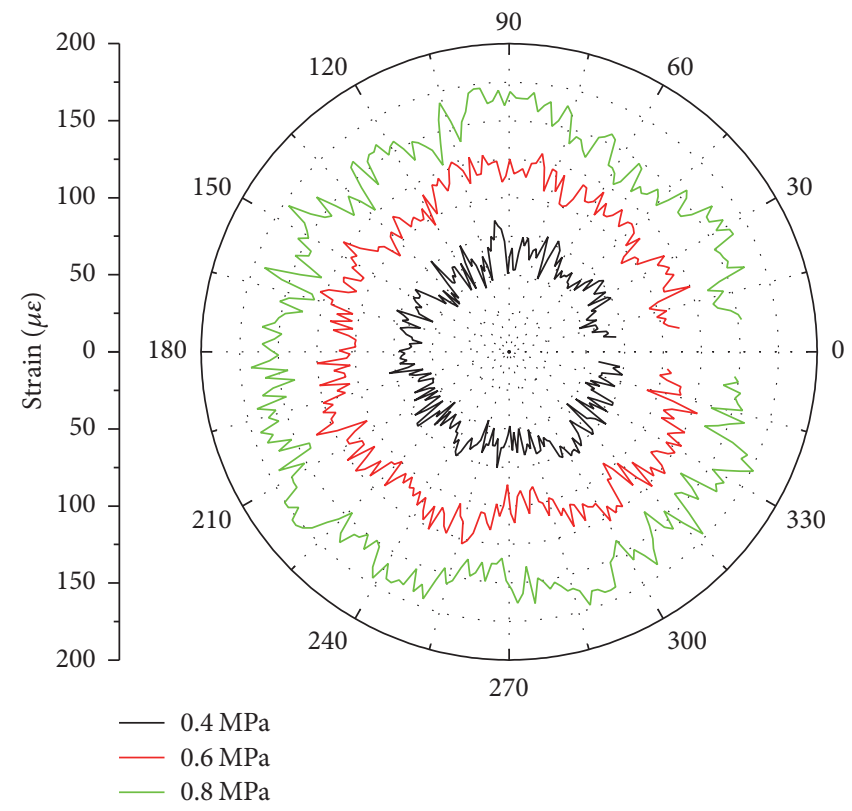

(c)

Figure 7: Strains measured using PEPFOSs for cases 1-3: (a) lower circle, (b) middle circle, and (c) upper circle.

experimental conditions as shown in Figure 4, the bottom of the experimental PCCP segment was clamped in the numerical simulations.

As singularities appeared in cases 4-7 (Figure 8), the numerical results were compared with the measurements only for cases 1-3. The averaged hoop strains for both PEPFOS and SWPFOS were compared using the numerical hoop strains listed in Table 2. For all three cases, the relative errors between the numerical data and measurements were less than $15 \%$. In load case 1 , the measured strains were slightly larger than the calculated strains. The actual accuracy of the PPP-BOTDA system is $\pm 20 \mu \varepsilon$; hence, the relative error is larger for a small strain. With the increase in the applied load, the measured PEPFOS strains moved closer to the numerical data. However, the SWPFOS strains were slightly smaller than those from numerical simulations and PEPFOS. PEPFOS is thus more sensitive than SWPFOS. In the numerical simulations, microcracks appeared in the coating at an inner pressure of $0.94 \mathrm{MPa}$ owing to the strain exceeding the $144 \mu \varepsilon$ cracking strain of mortar. The applied inner pressure in load case 4 was higher than the load that induces cracking. Overall, both sensors exhibited reasonable 
TABLE 2: Average measured and numerical hoop strains for load cases 1-3.

\begin{tabular}{llcc}
\hline Case & 1 & 2 & 3 \\
\hline Average hoop strain from SWPFOS $(\mu \varepsilon)$ & 60 & 80 & 100 \\
Average hoop strain from PEPFOS $(\mu \varepsilon)$ & 65 & 90 & 115 \\
Average hoop strain from FE simulation $(\mu \varepsilon)$ & 58 & 87 & 116 \\
\hline
\end{tabular}

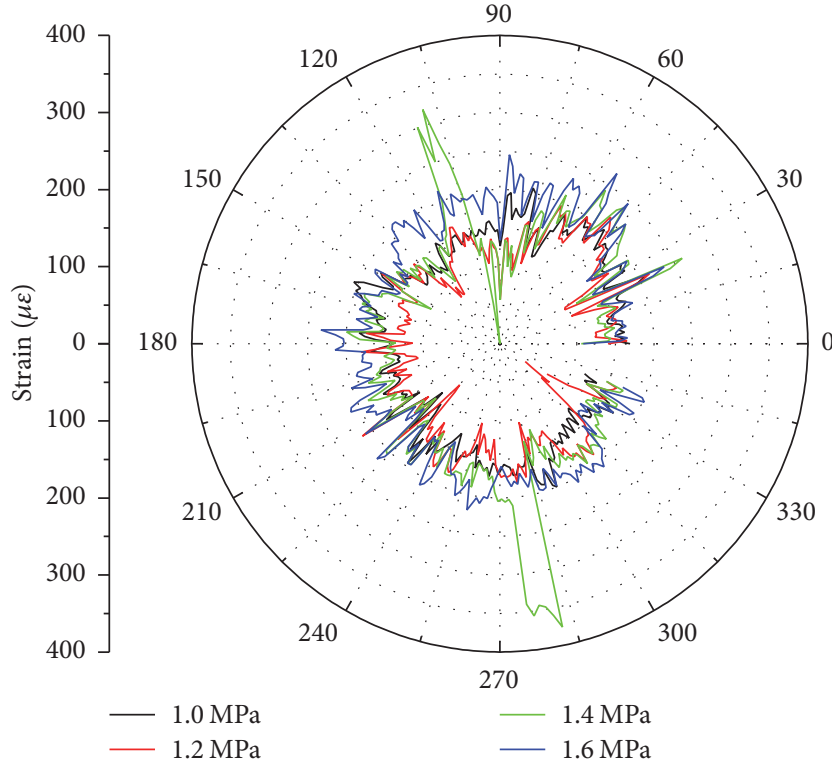

(a)

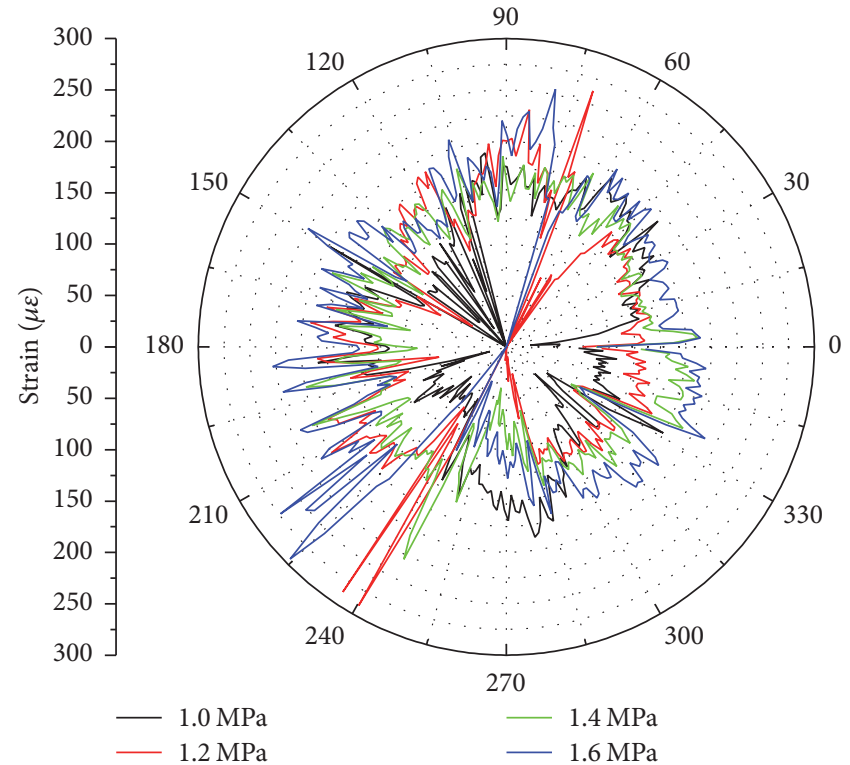

(b)

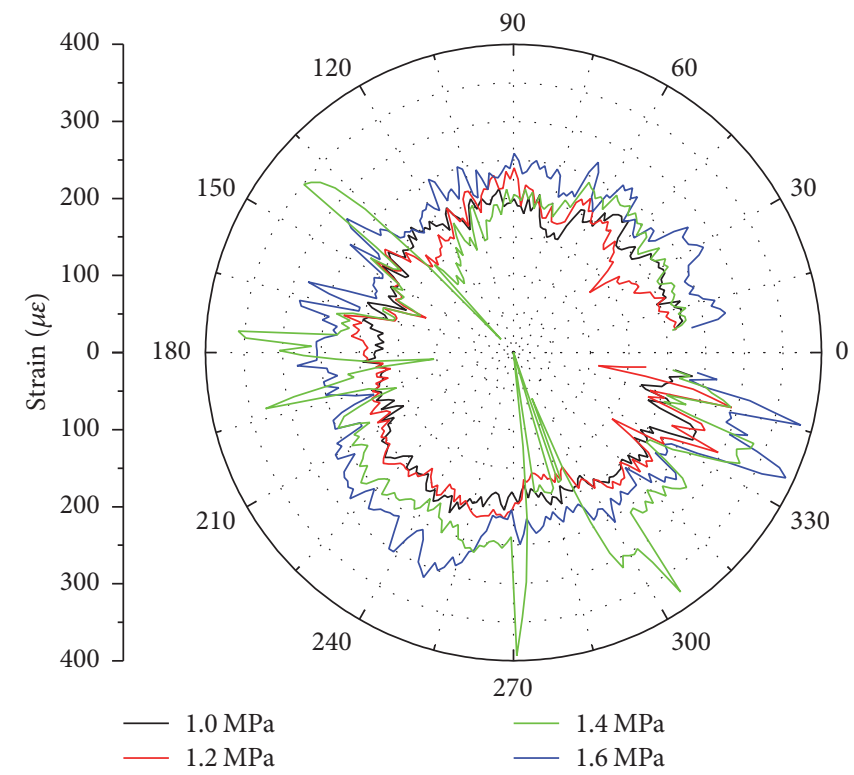

(c)

FiguRE 8: Strains measured using PEPFOSs for cases 4-7: (a) lower circle, (b) middle circle, and (c) upper circle.

distributed strain measurement accuracy when the strain was lower than the cracking strain of the mortar coating.

In case 4, which corresponded to an inner pressure of 1.0 $\mathrm{MPa}$, the BOTDA strain sensors could detect cracks in the coating. Figure 10 presents the numerical results of hoop strains in cases 4-6. The simulation results reveal that the crack zones and plastic strains increase with the applied load. The computed strains in the uncracked (unaffected) regions were in good agreement with the distributed measurements, with the exception of irregular point, the measured strains 


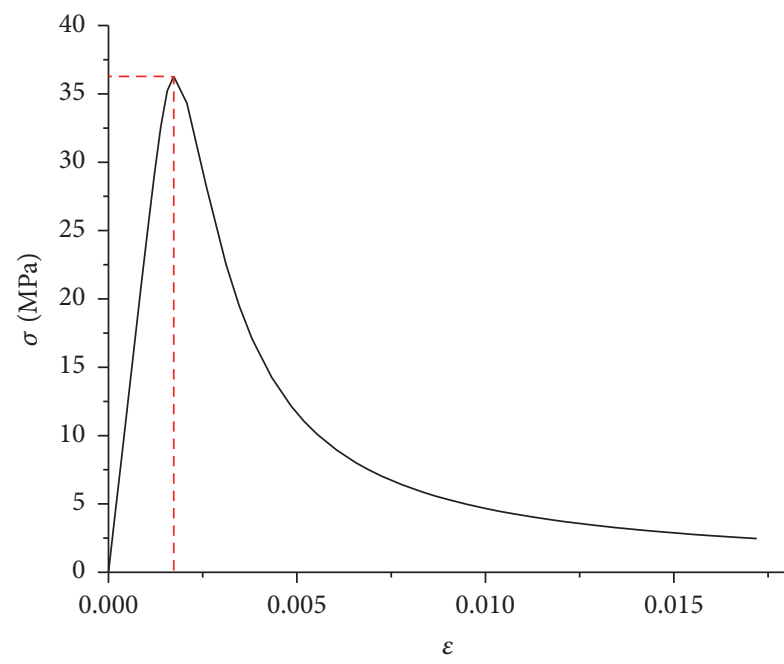

(a)

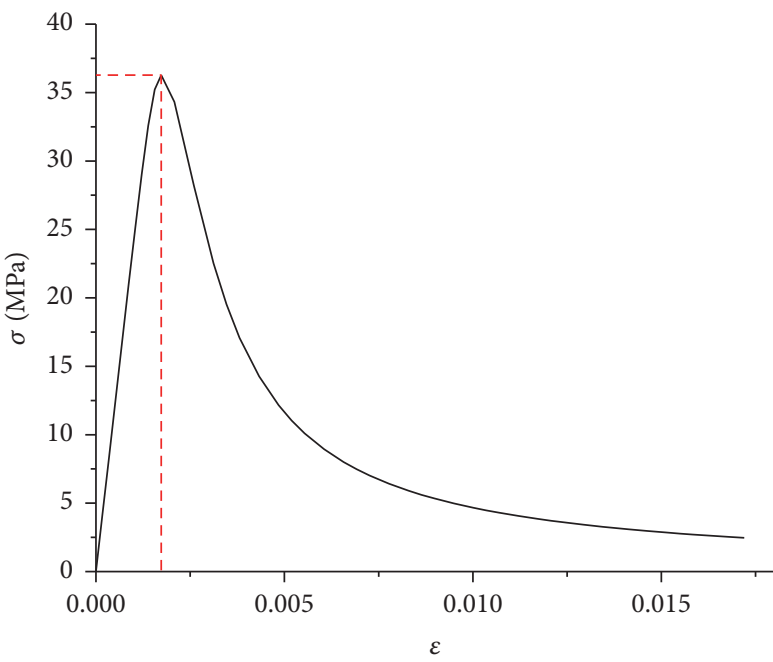

(c)

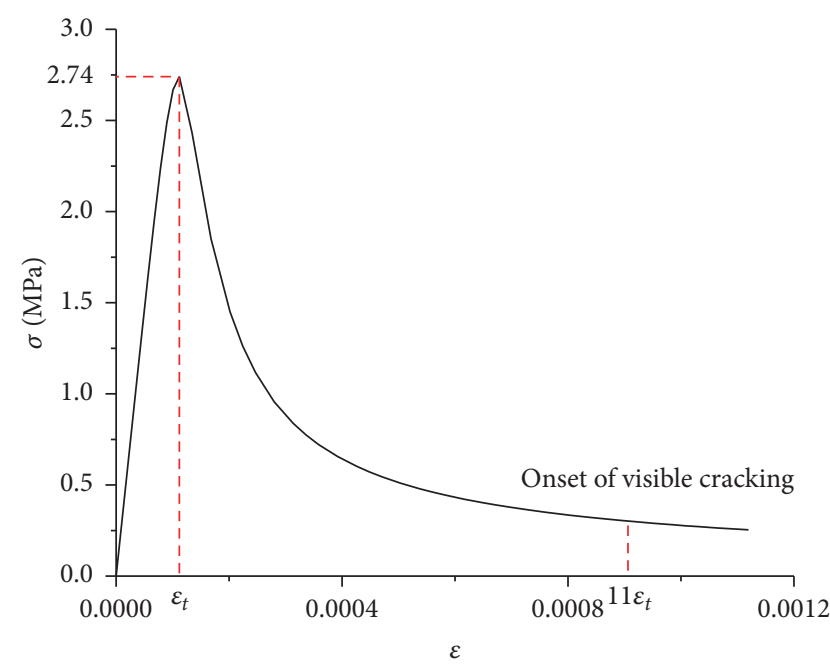

(b)

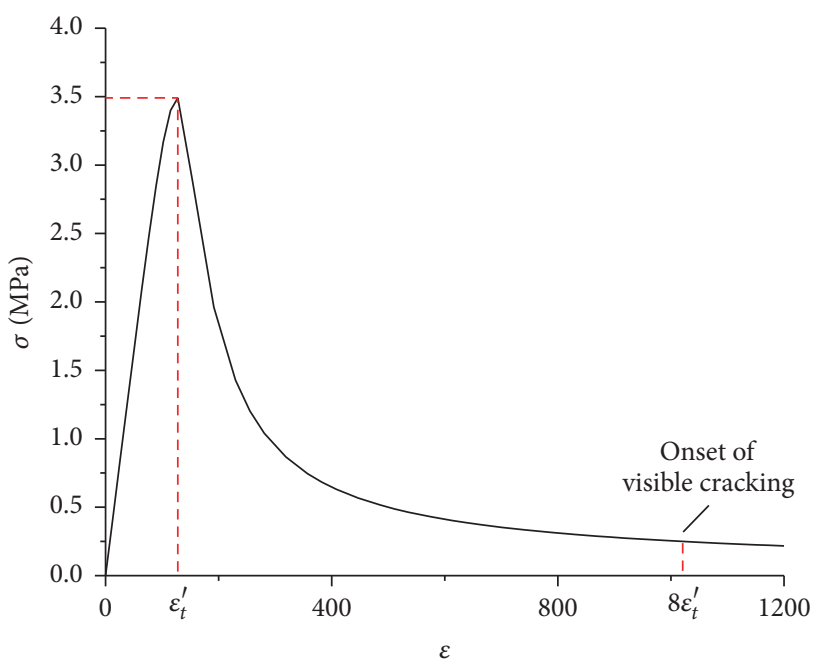

(d)

FIGURE 9: Stress-strain curves of concrete and cement mortar: (a) concrete under compression, (b) concrete under tension, (c) mortar under compression, and (d) mortar under tension.

at which were lower than the computed values; this can be attributed to the sensing cable bridging the mortar coating cracks, smoothening their singularity. According to the ANSI/AWWA C304 standard [17], the critical strain that produces visible cracks is $1152 \mu \varepsilon$. The calculation data indicate that visible cracks did not appear under any of the applied loads, the largest of which were much lower than $1152 \mu \varepsilon$. The computation results indicated that no damage occurred in the core, cylinder, and prestressing wires, thus validating the reliability of the proposed distributed FOS measurement method for detecting early damage in largediameter PCCPs.

It should be noted herein that the authors did not use the numerical simulation to validate the existence of structural damage in PCCP coating. The purpose of the numerical simulation is to interpret the experimental phenomenon on the basis of the damage criterion listed in the codes. As shown in the measured strains for SWPFOSs and PEPFOSs, the strain in the mortar coating in cases $4-7$ is larger than the critical strain corresponding to the peak stress, indicating that the mortar coating has entered the nonlinear damage stage because the applied internal pressures in cases 4-7 are much larger than the design value (i.e., $0.6 \mathrm{MPa}$ ). In combination of the measurements with the numerical results, it is reasonably deduced that the mortar coating can be identified as being in a damaged state from the irregularities in the distributed strain measurements.

\section{Conclusions}

This paper proposed the use of BOTDA strain sensors for detecting the structural deteriorations of PCCPs and discussed the selection of appropriate sensing cables and their installation techniques for accurate measurements. The feasibility of the proposed approach was studied through fullscale experiments on large-diameter PCCPs and two types of 
LE, LE22 (CSYS-1)

(Avg: $75 \%$ )

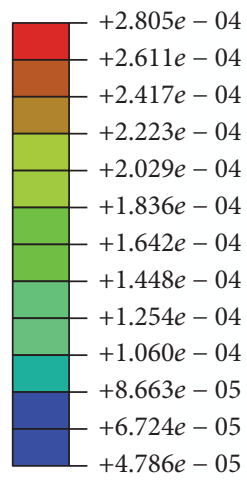

Max: $+2.805 e-04$

Elem: SHAJIANG-1.2259

Node: 5815

Min: $+4.786 e-05$

Elem: SHAJIANG-1.2260

Node: 5816

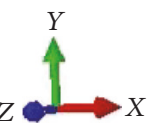

ODB: $11558.0 \mathrm{db}$ Abaqus/Standard 6.14-1

Step: Step-10

Increment 137: Step Time $=1.000$

Primary Var: LE, LE22 (CSYS-1)

Deformed Var: $U$ Deformation Scale Factor: +1.000 e+00

(a)

LE, LE22 (CSYS-1)

(Avg: 75\%)

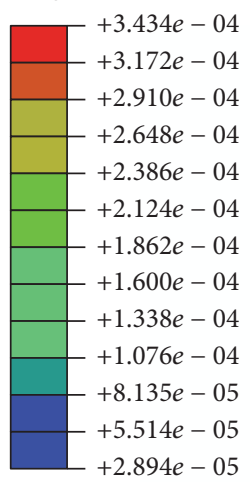

Max: $+3.434 e-04$

Elem: SHAJIANG-1.5489

Node: 11414

Min: $+2.894 e-05$

Elem: SHAJIANG-1.5488

Node: 11908
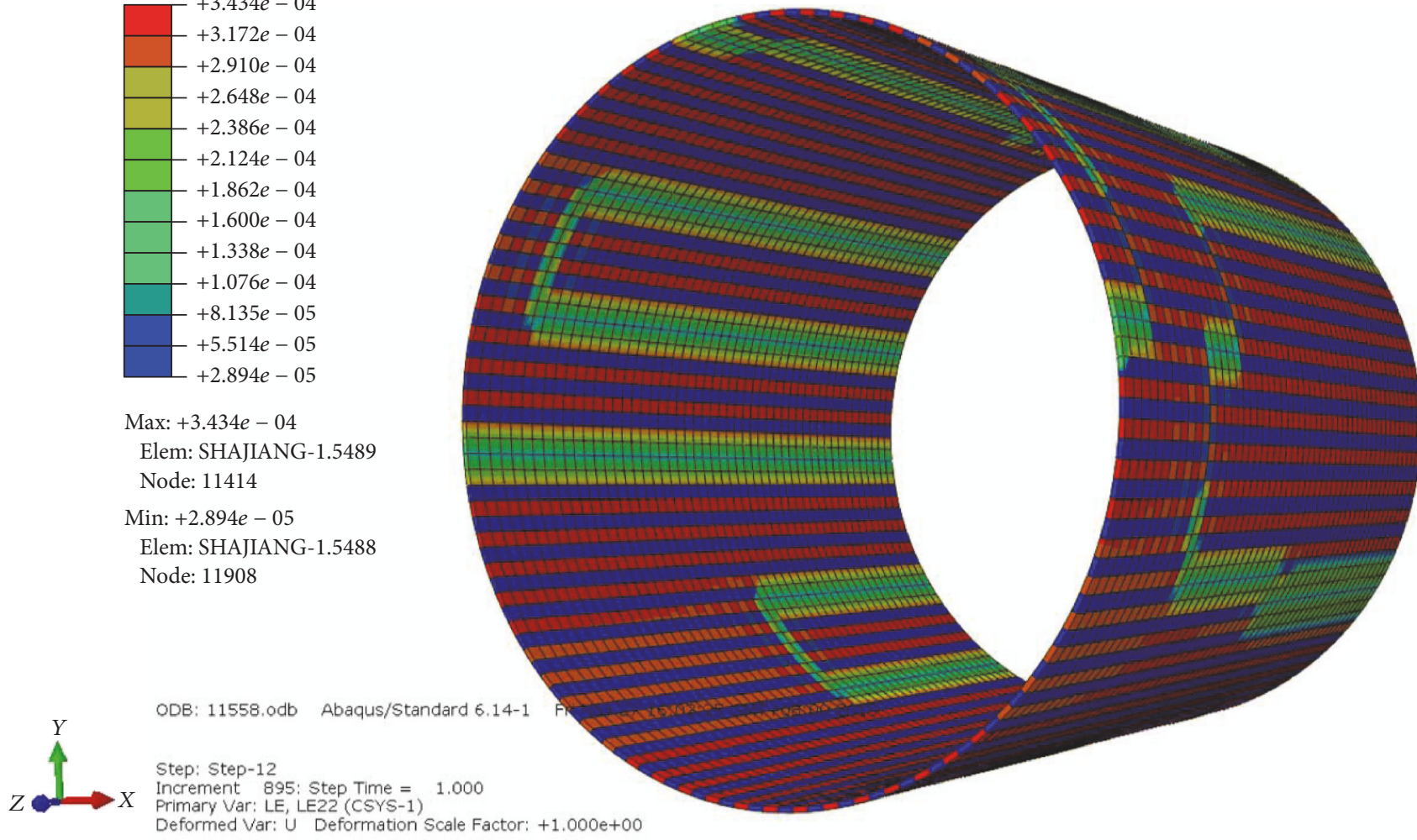

(b)

FIgure 10: Continued. 


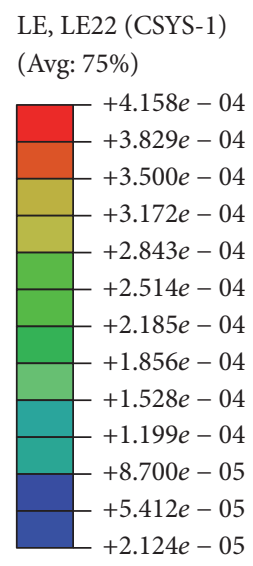

Max: +4.158e - 04

Elem: SHAJIANG-1.5489

Node: 11414

Min: $+2.124 e-05$

Elem: SHAJIANG-1.5488

Node: 11908

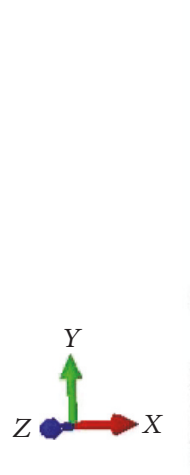

ODB: $11558 . \mathrm{odb}$

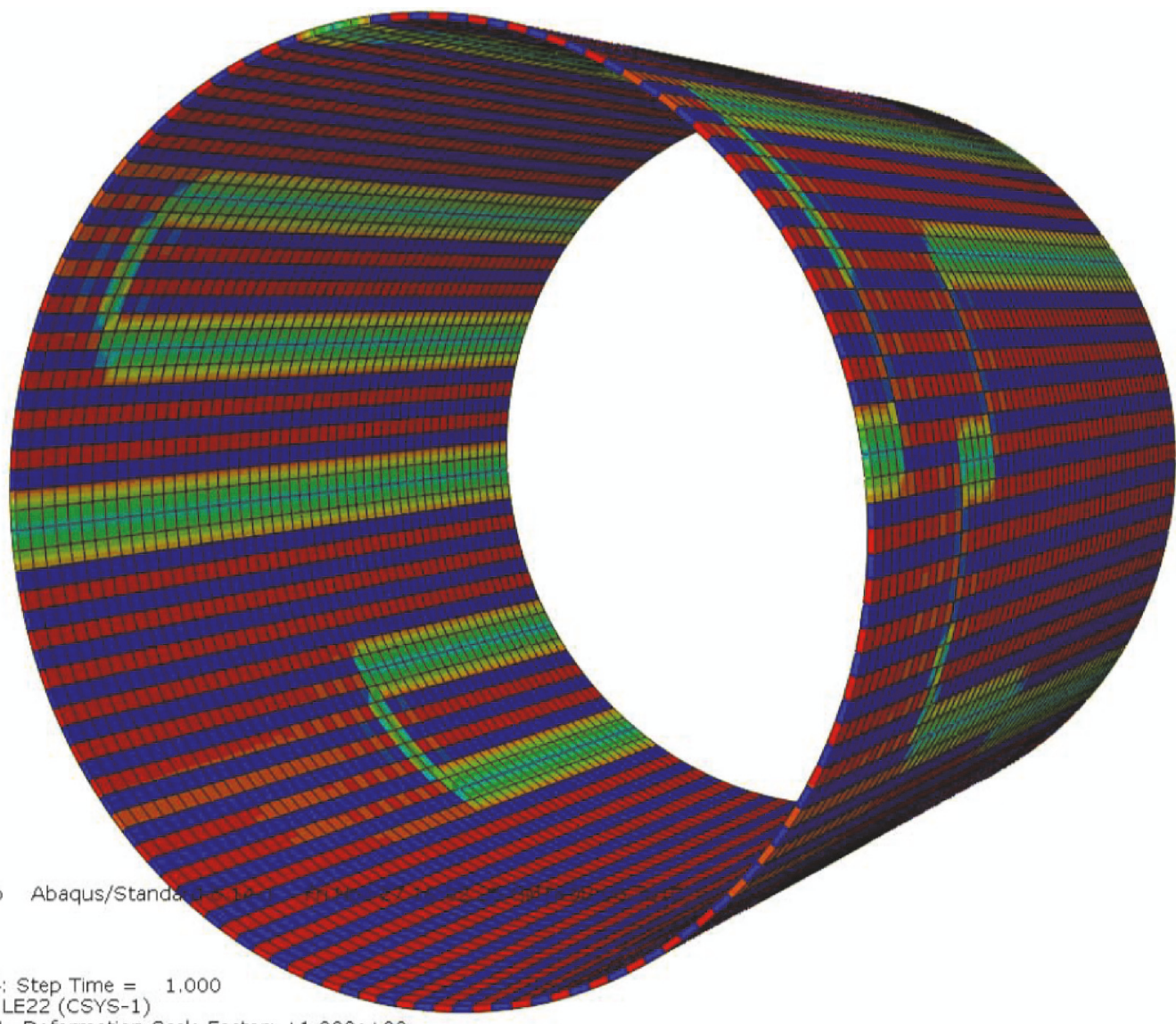

Increment $254:$ Step Time $=1,000$

Primary Var: LE, LE22 (CSYS-1)

Deformed Var: U Deformation Scale Factor: $+1,000 e+00$

(c)

FIGURE 10: Numerical hoop strains in the coating: (a) case 4, (b) case 5, and (c) case 6.

sensing cables, SWPFOSs and PEPFOSs. In the experiments, the hoop strain of the test PCCPs was monitored at various inner pressures. The measured data showed that both the SWPFOS and the PEPFOS could acquire the global strain shapes of the PCCP at both the pre- and postcracking stages. In addition, both sensing cables survived the propagation of microcracks in the coating. Nevertheless, PEPFOS was found to be superior in damage detection owing to its greater sensitivity to mortar cracking. These experimental results were successfully verified through numerical simulation, thus validating the use of BOTDA sensors for detecting early damage in large-diameter PCCPs. Additional studies are required for the field application of the proposed method, particularly to examine its durability in the field, where more complex service states may be present.

\section{Conflicts of Interest}

The authors declare that they have no conflicts of interest.

\section{Acknowledgments}

This article is based on a study supported by the National Key Research and Development Program (Grant 2016YFC0802402) and the National Natural Science Foundation of China (Grant 51378088).

\section{References}

[1] S. Ge and S. Sinha, "Failure analysis, condition assessment technologies, and performance prediction of prestressed-concrete cylinder pipe: State-of-the-art literature review," Journal of Performance of Constructed Facilities, vol. 28, no. 3, pp. 618-628, 2014.

[2] R. A. Lewis and P. Fisk, "Detection of prestressed concrete cylinder pipe thinning from hydrogen sulfide deterioration," in Proceedings of the Pipeline Division Specialty Conference, pp. 965-979, Houston, Tex, USA, 2005.

[3] J. J. Galleher and M. T. Stift, "Internal inspection and database development of PCCP," in Proceedings of the International Pipelines Conference, pp. 721-730, Reston, Va, USA, 1998.

[4] M. Holley, R. Diaz, and M. Giovanniello, "Acoustic monitoring of prestressed concrete cylinder pipe a case history," in Proceedings of the Pipelines 2001: Advances in Pipeline Engineering and Construction, Reston, VA, Usa, July 2001.

[5] F. Ansari, "Practical implementation of optical fiber sensors in civil structural health monitoring," Journal of Intelligent Material Systems and Structures, vol. 18, no. 8, pp. 879-889, 2007. 
[6] B. Glisic and Y. Yao, "Fiber optic method for health assessment of pipelines subjected to earthquake-induced ground movement," Structural Health Monitoring, vol. 11, no. 6, pp. 696-711, 2012.

[7] X. Feng, J. Zhou, C. Sun, X. Zhang, and F. Ansari, “Theoretical and experimental investigations into crack detection with BOTDR-distributed fiber optic sensors," Journal of Engineering Mechanics, vol. 139, no. 12, pp. 1797-1807, 2013.

[8] X. Feng, X. Zhang, C. Sun, M. Motamedi, and F. Ansari, "Stationary wavelet transform method for distributed detection of damage by fiber-optic sensors," Journal of Engineering Mechanics, vol. 140, no. 4, Article ID 04013004, 2014.

[9] D. Meng, F. Ansari, and X. Feng, "Etection and monitoring of surface micro-cracks by PPP-BOTDA," Applied Optics, vol. 54, no. 16, pp. 4972-4978, 2015.

[10] T. Horiguchi, T. Kurashima, and M. Tateda, "A technique to measure distributed strain in optical fibers," IEEE Photonics Technology Letters, vol. 2, no. 5, pp. 352-354, 1990.

[11] M. A. Soto, M. Taki, G. Bolognini, and F. Di Pasquale, "Optimization of a DPP-BOTDA sensor with $25 \mathrm{~cm}$ spatial resolution over $60 \mathrm{~km}$ standard single-mode fiber using Simplex codes and optical pre-amplification," Optics Express, vol. 20, no. 7, pp. 6860-6869, 2012.

[12] X. Angulo-Vinuesa, S. Martin-Lopez, P. Corredera, and M. Gonzalez-Herraez, "Raman-assisted brillouin optical timedomain analysis with sub-meter resolution over $100 \mathrm{~km}$," Optics Express, vol. 20, no. 11, pp. 12147-12154, 2012.

[13] K. Kishida and C.-H. Li, "Pulse Pre-Pump-BOTDA technology for new generation of distributed strain measuring system," in Proceedings of the 2nd International Conference on Structural Health Monitoring of Intelligent Infrastructure, (SHMII '05), pp. 471-477, November 2006.

[14] S. A. Arnaout, "Investigation of mechanical restraint joint leaks on 48-inch prestressed concrete cylinder pipe," in Proceedings of the Pipeline Division Specialty Conference 2005, pp. 583-591, Houston, Tex, USA, 2005.

[15] K. Cao, Study on durability of distributed optical fiber for pipeline monitoring. [M.S. thesis], Faculty of Infrastructure Engineering, Dalian University of Technology, Dalian, China, 2016.

[16] Abaqus, "Concrete damaged plasticity. 19.6.3 of the Abaqus Analysis User's Manual 6.9”.

[17] ANSI/AWWA C304-2007, Design of Prestressed Concrete Cylinder Pipe, American Water Works Association, Denver, CO, USA, 2007. 


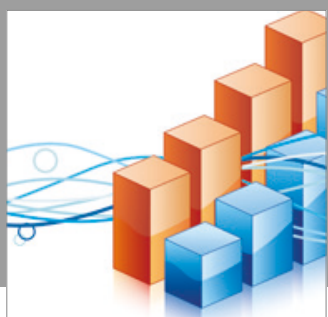

Advances in

Operations Research

vatersals

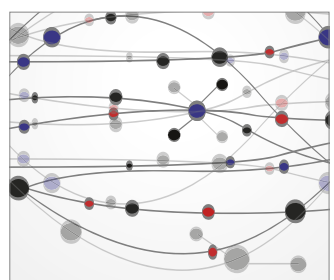

\section{The Scientific} World Journal
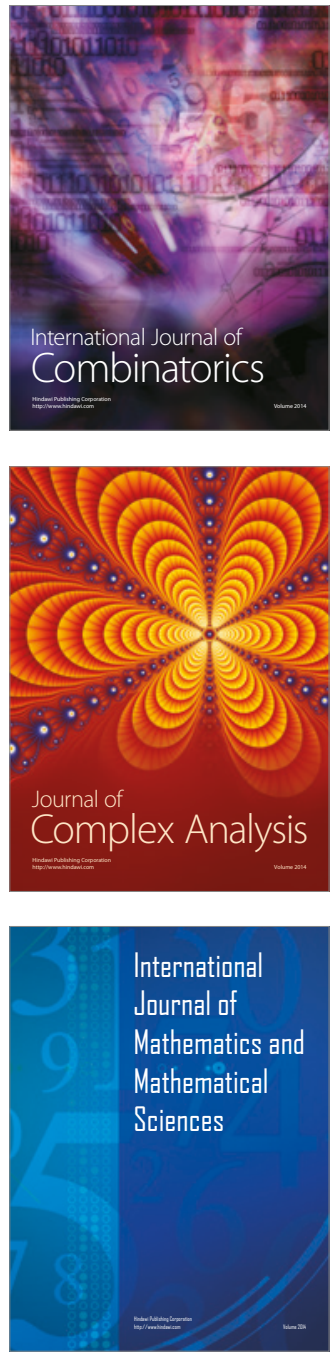
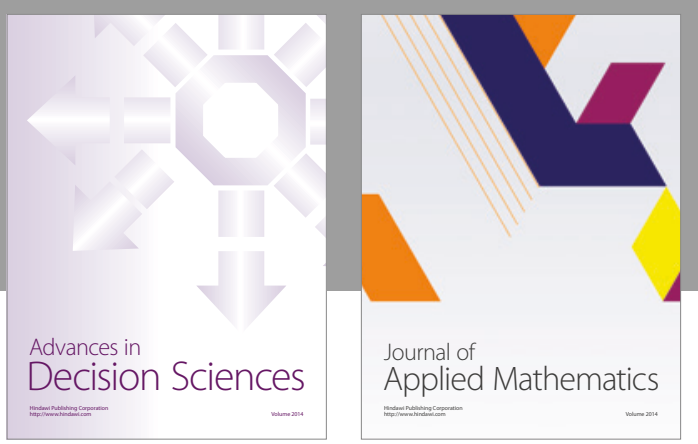

Algebra

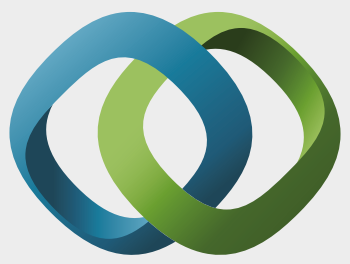

\section{Hindawi}

Submit your manuscripts at

https://www.hindawi.com
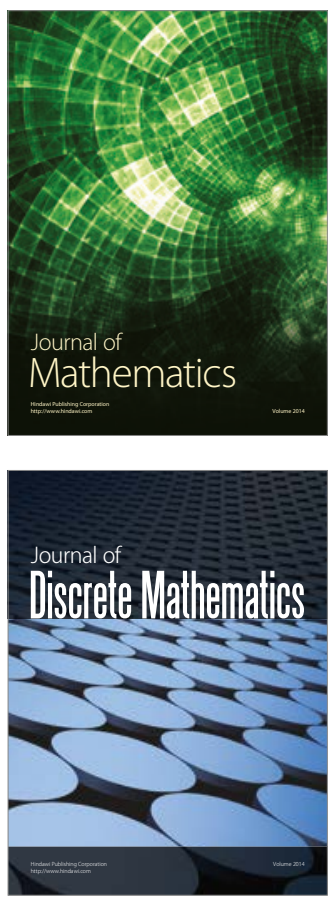

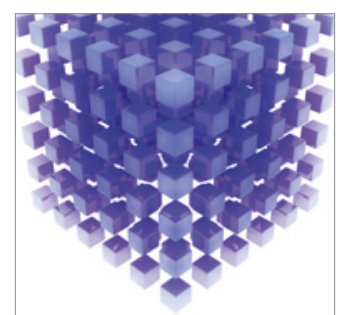

Mathematical Problems in Engineering
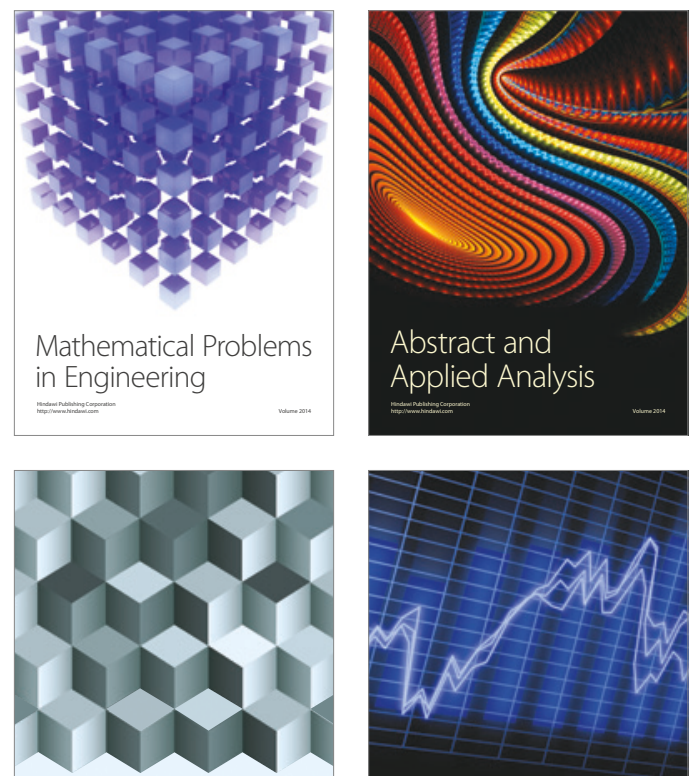

Journal of

Function Spaces

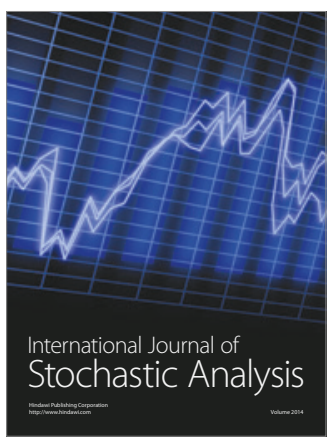

Probability and Statistics
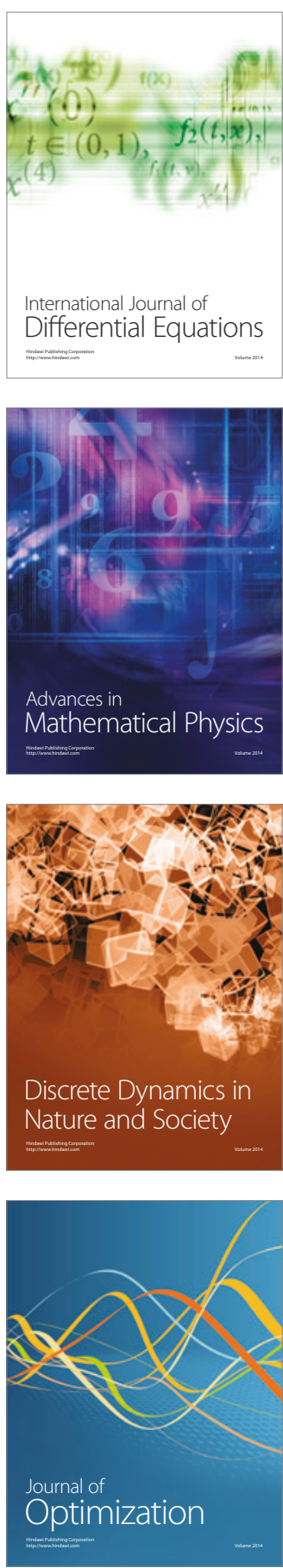